\title{
Workshop de Inovação com Tecnologias Educacionais: Um Relato de Experiência
}

\author{
Elvis Medeiros de Melo, Adriana Virgínia Azevedo, Débora Karoline Silva de \\ Azevedo, Dennys Leite Maia
}

Instituto Metrópole Digital - Universidade Federal do Rio Grande do Norte (UFRN) Av. Sen. Salgado Filho, 3000 - Lagoa Nova, CEP: 59.078-970 - Natal - RN - Brasil

\{elvismedeiros.mm, adrianavma zevedo, deboraazevedoo\} @gmail.com, dennys@imd.ufrn.br

\begin{abstract}
This article aims to report a teacher training event for the use of educational technologies within a subject of the Bachelor of Information Technology undergrad course with emphasis on Educational Technologies. About 80 teachers from public schools of state of Rio Grande do Norte participated in the training, which was a limitation of the physical capacity of the laboratories reserved for training. Teachers participated in workshops on Google's tools from an educational perspective and the use of smartphones in the classroom, as well as learning about and being ready to use online educational platforms. The evaluation was positive and the next editions will be supported by a university research group.

Resumo. Este artigo tem o objetivo de relatar a formação de professores para o uso de tecnologias educacionais no âmbito de uma disciplina do curso de Bacharelado em Tecnologia da Informação com ênfase em Tecnologias Educacionais. Participaram da formação cerca de 80 professores da rede pública do estado do Rio Grande do Norte, limitação da capacidade física dos laboratórios reservados para a formação. Os professores participaram de oficinas sobre as ferramentas do Google sob perspectiva educacional e o uso dos smartphones na sala de aula, além de conhecer e se apropriar de plataformas educacionais online. A avaliação foi positiva e as próximas edições contarão com apoio de um grupo de pesquisa da universidade.
\end{abstract}

\section{Introdução}

A tecnologia é uma agente de mudança e as grandes inovações tecnológicas podem resultar em mudanças inteiras de paradigma. A rede de computadores, conhecida como internet, é uma dessas inovações. Em decorrência disso, uma mudança importante também pode estar surgindo na maneira como os materiais educacionais são projetados, desenvolvidos e apresentados para aqueles que desejam aprender. A necessidade de práticas inovadoras que utilizam tais ferramentas é eminente quando observamos a rápida difusão de dispositivos móveis e de tecnologia na vida dos estudantes.

Durante a disciplina de Práticas Educacionais Inovadoras com Tecnologias Digitais (PEITD) ministrada no semestre 2018.2 do curso de Bacharelado em Tecnologia da Informação no Instituto Metrópole Digital/UFRN, foi discutido que uma grande deficiência na evolução da utilização de práticas inovadoras é a falta de conhecimento e de preparação. Os discentes da PEITD decidiram realizar como projeto da disciplina o Workshop sobre Inovações em Tecnologias Educacionais (WITE) sendo 
VIII Congresso Brasileiro de Informática na Educação (CBIE 2019)

Anais do XXV Workshop de Informática na Escola (WIE 2019)

oferecido principalmente a professores da educação básica. Neste artigo será relatado o desenvolvimento do WITE, as oficinas oferecidas e as impressões sobre a formação.

Esse artigo foi estruturado com: Introdução, onde está exposto a problematização que levou ao desenvolvimento do WITE; Fundamentação Teórica, na qual apresentamos experiências similares ao WITE; o Relato de Experiência, na qual detalhamos os procedimentos adotados em cada oficina e a sua aplicação, por último, as Conclusões.

\section{Fundamentação Teórica}

Buscando analisar relatos de experiência com formação de professores para o uso de Tecnologias Digitais de Informação e Comunicação (TDIC), em pesquisa bibliográfica, observamos que ainda são pontuais as iniciativas, assim como as publicações dos mesmos. Em Alves e Batista (2016) foi realizada uma pesquisa documental para analisar a influência da formação docente na prática pedagógica dos pedagogos com o uso das TDIC na educação. Os autores concluem que a formação recebida não dá subsídios suficientes para que esses professores consigam usar as TDIC em suas salas de aula. Observamos que diversos tipos de formação de professores em processo continumm [UNESCO 2016] tem acontecido em diversos lugares do Brasil.

Arruda, Siqueira e Castro-Filho (2016) trabalharam com professores do ensino fundamental que estavam inscritos em um curso de formação sobre o uso de tecnologias digitais no ensino. Já Araújo, Silva e Aranha (2016) apresentam a condução e avaliação de uma experiência de formação de professores do ensino básico da rede pública do estado do Rio Grande do Norte para a utilização de etapas iniciais do Game Design, a fim de criar jogos digitais como apoio ao processo ensino e aprendizagem no âmbito do programa Mais Educação. Ainda no contexto potiguar, Farias et al. (2018) apresentam os resultados obtidos durante uma experiência na oficina "Práticas Pedagógicas Colaborativas na formação das habilidades do profissional do futuro" realizada com professores da educação básica. O objetivo foi apresentar ferramentas digitais de apoio a práticas pedagógicas colaborativas, produção de questionários e enquetes interativas, assim como uso de ambiente colaborativo gamificado.

Todos os autores citados consideram a importância de um aumento da carga-horária da oficina, visto a numerosidade de conteúdos apresentados, além de dividir a turma por níveis de conhecimento previamente informados. Relatamos os procedimentos adotados para a ocorrência do WITE assim como as impressões.

\section{Relato da Experiência}

O WITE foi idealizado para ocorrer entre dois dias, com carga horária de 20 horas. Os dias foram pensados pela organização levando-se em consideração o horário no qual os professores estariam livres para participar de uma formação. A escolha imediata foi o dia do sábado por ser mais conveniente para os formadores, e um dia livre para os professores poderem participar da formação. As datas foram fechadas nos dias 24 de novembro e $1^{\circ}$ de dezembro de 2018 , a ocorrer nos turnos matutino e vespertino. Para a retirada do certificado, no momento da solicitação da inscrição, foi deixado claro que os professores precisaram participar de todos os momentos, e para a certificação, pelo menos de $75 \%$ de presença, ou seja, a participação em três das quatro oficinas.

Os temas foram escolhidos por meio de votação dos discentes, utilizando como base a primeira edição do evento que ocorreu em 2016 e também foi idealizada e realizada por estudantes da mesma disciplina. Dentre os temas, as oficinas abordaram 
VIII Congresso Brasileiro de Informática na Educação (CBIE 2019)

Anais do XXV Workshop de Informática na Escola (WIE 2019)

como utilizar o Google Drive, o Google Formulários e o Google Sala de Aula; o uso pedagógico do smartphone em atividades e recursos educativos digitais para a aula. Cada grupo elaborou a sequência da formação, de acordo com a sequência de atividades do WITE, e ficaram responsáveis por um dos quatro turnos do evento.

Para as inscrições, elaboramos e divulgamos via WhatsApp um survey de inscrições, no qual explicamos as condições de participação. Pedimos para os professores se identificarem e, na escolha final, demos preferência à professores da rede pública. Oferecemos 80 vagas, dividindo o grupo em duas turmas. Apesar disso, contamos com a demonstração de interesse de mais de 500 professores potiguares.

$\mathrm{Na}$ primeira oficina, o objetivo geral foi desenvolver práticas colaborativas utilizando o Google Drive como ferramenta de apoio ao ensino. Para tanto, os objetivos específicos foram delineados em: Criar e configurar uma conta Google; Conhecer o ambiente do Google Drive; Compreender o uso básico das principais ferramentas Google e Gerenciar e compartilhar documentos online e usar colaborativamente as ferramentas de edição dos aplicativos Docs e Slide. Foram utilizadas aulas expositivas com o uso de projetor para apresentação do conteúdo a ser abordado e uma prática direcionada para fixação do conteúdo já visto, com o uso de algumas funcionalidades que a ferramenta disponibiliza.

Na segunda oficina, o objetivo foi utilizar o Google Sala de Aula e o Google Formulários como ferramentas pedagógicas. Quando definido esse objetivo, os específicos foram delineados: Compreender as ferramentas selecionadas; Explorar as funcionalidades dessas ferramentas; Criar Sala de aula virtual e Formulários utilizando as principais funcionalidades das ferramentas; Desenvolver, vivenciar e compartilhar práticas com simulações de situações reais utilizando o Google Sala de Aula e o Google Formulário. Durante toda a oficina ocorreu a busca do conhecimento das ferramentas, principalmente o Google Sala de Aula, pela exploração das funcionalidades, criando conexões com as práticas desenvolvidas pelo professor em uma sala de aula física. Apresentou-se a estrutura básica do Google Formulários, além da criação de formulário pelo cursista. Ao final desse momento, ele deverá apresentar o formulário com a proposta utilizada, abordando assuntos e atividades sobre TDIC utilizando Sala de Aula Invertida e Ensino Híbrido.

$\mathrm{Na}$ terceira oficina, o cursista utilizou o celular como um recurso pedagógico na sala de aula. Para tanto, teve como tarefa: Sincronizar a conta do email no celular; Aprender como configurar um ambiente de aprendizado (configuração de notificações); Conhecer as ferramentas que constam originalmente no celular; Conhecer ferramentas do celular que podem ser usadas nas aulas (online e offline); Usar o celular em uma prática educacional. A provocação inicial foi a integração dos conteúdos anteriores para o ambiente mobile. Os professores foram questionados quanto aos assuntos relativos ao uso pedagógico do smartphone, como método de retomada dos conceitos prévios, e também da atividade $\mathrm{EaD}$ de elaboração dos questionários aplicados com seus alunos. Foram explanadas situações-problema com o uso do smartphone. Neste momento, apresentamos algumas ferramentas que podem ser utilizadas na sala de aula, mostrando soluções de trabalhos realizados por professores (relatos de experiência publicados) que precisam ou não do uso da internet móvel, desenvolvidas em diferentes disciplinas na Educação Básica.

$\mathrm{Na}$ última oficina, os professores aprenderam sobre a utilização dos Recursos Educativos Digitais no processo de ensino-aprendizagem. Para tanto, eles conheceram sobre os recursos educativos digitais; Entenderam os benefícios dos recursos educativos 
VIII Congresso Brasileiro de Informática na Educação (CBIE 2019)

Anais do XXV Workshop de Informática na Escola (WIE 2019)

digitais no processo de ensino-aprendizagem; Reconheceram recursos educativos digitais offline e/ou online. A história da evolução da educação e suas tecnologias foram comentados no momento desta oficina. Foi proposta uma atividade exploratória sobre os repositórios e levantadas questões sobre as condições das escolas dos professores.

Os alunos da PEITD se dividiram nas funções administrativas e de formação durante todo o correr do WITE, por exemplo, enquanto um grupo apresentava as oficinas nas duas turmas formadas, os demais cuidavam da parte administrativa, de suporte dentro das salas e do coffee break. Vale salientar que as formações aconteceram no período de final de semestre e nos sábados, o que facilitou a reserva de laboratórios de informática no Instituto Metrópole Digital.

Na primeira oficina, percebemos a participação do grupo de professores que tinham se inscrito, com poucas ausências. Vale salientar que os professores se inscreveram para participar uma formação fora do seu horário de trabalho, o que mostra o interesse tanto pela temática quanto o comprometimento com o seu desenvolvimento profissional e a inserção das tecnologias em suas práticas. Durante suas falas, percebemos que os professores consideram importante a inserção das tecnologias na sala de aula e a necessidade de apropriação de tais ferramentas.

$\mathrm{Na}$ oficina da tarde, os professores utilizaram outras ferramentas do Google, como o Google formulários e o Google sala de aula. Com as atividades realizadas na oficina, percebemos um engajamento dos docentes ao proporem atividades com o uso das ferramentas. Um fato a ser destacado e muito comentado durante a formação da tarde é a aplicabilidade na gestão da sala proporcionada pelas ferramentas do Google. Apesar de os municípios e o estado possuírem o próprio sistema de gestão, os professores avaliaram as ferramentas como possibilidades nas suas aulas pela praticidade e facilidade do uso, tendo em vista também que alunos com smartphone já possuem conta do Google.

No segundo dia, contamos com um número menor de participantes. Não sabemos ao certo o motivo, mas a adesão foi menor em relação ao primeiro dia. Os professores foram instruídos a pensar nas ferramentas para o smartphone de maneira diferenciada. Precisaram elaborar um plano de aula colaborativo usando alguma ferramenta online ou offline mostradas durante a oficina. O comando da atividade não deixou preso o recurso, fazendo com que uma riqueza de recursos aparecesse durante a fala e a apresentação dos recursos pelos professores.

No turno da tarde, o público da manhã se manteve. Os docentes tiveram contato com recursos educativos digitais diversos, como a Plataforma OBAMA, o Ambiente ATHENA, entre outros. Conheceram recursos online e offline para o computador, se apropriando de tais ferramentas por meio da exploração de tais recursos e a sua apresentação para a turma levando em consideração aspectos como o público alvo, o objetivo dos recursos, porque usariam em sala de aula e qual assunto trabalharia o recurso.

Ao final, os professores avaliaram o WITE por meio de um survey elaborado pelo Google formulários. Nele, os participantes deram informações, sugestões e opiniões no sentido de buscar nos próximos eventos as adequações necessárias às ações planejadas. Foram avaliados aspectos como a divisão dos temas, a carga-horária e se indicaria a outras pessoas a participação no WITE.

Entre os resultados, os professores elogiaram a iniciativa e recomendam a participação de outras pessoas no evento. Entre as considerações, comentaram sobre a grande quantidade de professores de suas escolas ficaram de fora da seleção e que 
achavam importante que o evento acontecesse outras vezes durante o ano com temas específicos, ao invés de todos de uma vez. A seguir, faremos algumas considerações que a formação nos proporcionou realizar.

\section{Conclusões}

No geral, observamos que os professores participaram das oficinas, tendo uma adesão bem maior ao primeiro dia. Inferimos também que os professores se engajaram em atividades de formação que acontecem em um dia completo, mas em dois sábados seguidos o engajamento fica mais comprometido. É importante pensar e planejar formações para ferramentas mais específicas e de interesse dos professores a ocorrer durante todo o ano. Concluímos que os professores se interessam mais por atividades que acontecem em apenas um dia, apesar de assuntos diferentes. Além disso, é interessante notar a grande quantidade de professores que solicitaram a participação no evento, chegando a casa de 500 inscrições, sendo necessária uma triagem por causa das limitações físicas e de pessoal. Isso mostra que os professores estão buscando se apropriar de ferramentas digitais para inovar em suas aulas.

Em próximas edições, o WITE acontecerá por meio do vínculo ao Grupo Interdisciplinar de Pesquisa e Estudos em Informática na Educação (GIIfE), no qual os docentes da instituição se prontificaram a serem responsáveis pela organização dos próximos eventos, a ocorrerem uma vez ao ano, de preferência próximo às férias escolares do Rio Grande do Norte, conforme sugeriram os professores.

\section{Referências}

Alves, F. C. S.; Batista, A. A. M. (2016) A Influência Da Formação Docente Nas Práticas Pedagógicas Com O Uso Do Computador. In: Anais do Congresso Regional sobre Tecnologias na Educação (Ctrl+E 2016).

Arruda, J.; Siqueira, L. M. R. C.; Castro- Filho, J.A. (2016) O uso de tecnologias digitais na facilitação da emergência de zonas de desenvolvimento proximal em sala de aula. In: Anais dos Workshops do Congresso Brasileiro de Informática na Educação (CBIE 2016).

Araújo, G. G.; Silva, T. R.; Aranha, E. (2016) A Construção de Jogos Digitais na Escola: um Relato de Experiência na Formação de Professores. In: Anais do XXII Workshop de Informática na Escola (WIE 2016).

Farias, F. L. O. et al. (2018) Práticas Pedagógicas Colaborativas utilizando Ferramentas Digitais: Um Relato de experiência na formação de educadores. In: Anais do XXIV Workshop de Informática na Escola (WIE 2018).

UNESCO (2016) Os desafios do ensino de matemática na educação básica. - Brasília : UNESCO ; São Carlos: EdUFSCar, 2016, 114 p. 